\title{
The pull toward the vacuum: Osteopathic medical education in the 1980s
}

\author{
MARK CUMMINGS, PhD
}

During the 1980s, the two major influences in osteopathic medical education were the increasingly large number of new DOs seeking internships and residencies and the loss of training sites as a result of the shrinking osteopathic hospital network. Owing mainly to a declining interest in primary care by young MDs, allopathic postdoctoral program directors, particularly in primary care specialties, began to actively recruit osteopathic physicians. An oversupply of positions on the allopathic postdoctoral side and an undersupply of residency positions in osteopathic postdoctoral programs contributed to a crossover trend. The programs approved by the Accreditation Council for Graduate Medical Education have made significant inroads in attracting DOs. It has reached the point where two out of every three DOs currently training in a primary care residency can be found in an allopathic program. If it continues, this pattern will have a significant impact on the character of osteopathic medical education.

The 1980s were not kind to the educational programs accredited by the American Osteo-

Portions of this article were presented at the meeting of the American Association of Colleges of Osteopathic Medicine, Dec 6, 1988, in Las Vegas, Nev.

Reprint requests to Mark Cummings, $\mathrm{PhD}$, assistant dean for medical education, New York College of Osteopathic Medicine of New York Institute of Technology, Old Westbury, NY 11568. pathic Association. The osteopathic hospital system underwent major convulsions as closures, conversions, or acquisitions took a number of facilities outside the osteopathic orbit. As a result, the number of postdoctoral opportunities in osteopathic facilities was greatly diminished. At the same time, the expansion in the number of osteopathic medical colleges that had occurred during the 1970 s produced a bumper harvest of new graduates, who now faced a shrinking osteopathic postdoctoral educational system with a barely adequate number of internships and a drastic undersupply of residency positions.

By and large, the osteopathic hospital network is located in rural and inner-city areas, and a goodly number of DOs practice medicine at these facilities. For generations, these same hospitals have faithfully served as training sites for students, interns, and residents. The average osteopathic teaching hospital has only 180 licensed beds. Because of limits in size and available services, these hospitals are best suited for internships and residencies in the primary care specialties-namely, family practice, general internal medicine, and pediatrics. Only a handful of osteopathic hospitals that are situated in large population centers possess the necessary educational components to sponsor residencies in surgical and subspecialty fields.

These unique osteopathic realities may, to a certain extent, help explain why so many DOs gravitate toward primary care. Those who venture outside the osteopathic medical fam- 
ily for postdoctoral education discover external realities having to do with the degree to which they are accepted in the eyes of MDs. Some doors of opportunity are open to DOs. They are routinely accepted into allopathic residencies in primary care areas, rehabilitation medicine, psychiatry, anesthesiology, neurology, and many of the subspecialties of medicine. In surgical fields, however, the doors remain almost entirely closed to them.

\section{Creation of the vacuum}

Trends in allopathic medical education have already created a spin-off effect on osteopathic residencies. For at least the past 10 years, graduates of allopathic medical schools have shown an increasing aversion to primary care fields and a much stronger interest in surgical and subspecialty disciplines. Concurrently, owing to the growth in medical knowledge and advances in technology, medicine has become increasingly fragmented into smaller and smaller units of expertise. In addition, there are very strong economic incentives for a physician's choosing a surgical or subspecialty area. (For example, for 1987 the average income for a pediatrician was $\$ 85,300$; for a family practitioner, $\$ 91,500$. At the same time, the average income for surgeons was $\$ 187,900$, and for radiologists, $\$ 180,700 .^{1}$ ) This discernible trend toward specialization comes at the expense of the primary care fields, which are increasingly being abandoned in allopathic medical circles. Directors of primary care residencies approved by the Accreditation Council for Graduate Medical Education (ACGME) have been recruiting osteopathic physicians in an attempt to fill the gaps in their own programs.

Several researchers, ${ }^{2-5}$ looking at different years and from different perspectives, all come to the same conclusion: the number of MDs entering primary care residency programs is measurably lower now than it was in the past. Historical patterns of specialty preference and attitudes of allopathic medical students toward primary care have dropped markedly. Interest in family practice among US allopathic medical students fell from $37 \%$ in 1978 to $16 \%$ in $1987 . .^{5(\mathrm{p} 251)}$ Overall, primary care disciplines attracted $36 \%$ of all US allopathic medical school graduates in 1982 but only $29.1 \%$ in 1987 - a drop of nearly $20 \%$ in 5 years. ${ }^{5(\mathrm{p} 252)}$ Information gathered from the AAMC Graduation Questionnaire and the MCAT Questionnaire suggests strongly that interest in primary care will still be declining in $1991 . .^{5(\mathrm{p} 251)}$ There is not the slightest indication that the downward curve will flatten out. In March of 1987,1988 , and 1989, when the National Resident Matching Program (NRMP) conducted its match, the biggest loser in the residency sweepstakes were family practice and internal medicine. ${ }^{3(\mathrm{pp} 102,103), 5(\mathrm{p} 251), 6}$

Young DOs graduating from their internships are directly feeling the pull toward the MD vacuum, as evidenced by the number who gravitate into allopathic residencies. The new opportunities for DOs to train in ACGMEapproved residencies have produced a direct impact on the primary care residency programs within the osteopathic medical profession. Unfortunately, this problem can only grow larger, because the pool of osteopathic candidates is limited (and there is no other way to fill it, unless the crossover trend to allopathic residencies can be reversed in the near future).

In the meantime, the residencies of the ACGME-approved programs can be filled with foreign medical graduates (FMGs), MDs, or DOs. The gradual decrease in the number of FMGs serving as residents (from $20.2 \%$ in 1979 to $15.6 \%$ in 1988 ) has only heightened the popularity of DOs. ${ }^{7(\mathrm{p} 1036)}$ Osteopathic residencies are limited solely to DOs. If, then, too many DOs select ACGME-approved programs, the viability of the osteopathic medical educational system will be threatened. What could easily develop is a lopsided educational structure in which DOs interested in surgical specialties train in osteopathic hospitals while those interested in all other medical disciplines train in allopathic residencies.

On paper, the current realities within the osteopathic and allopathic medical worlds seem to be a perfect fit. On the one hand, the osteopathic medical profession has too few training positions and too many graduates seeking residencies. Young DOs cannot count on the 
availability of AOA-approved residencies and by necessity apply to ACGME-approved programs. On the other hand, the allopathic primary care residency programs have experienced a shortfall in the number of MD applicants. The DOs are an attractive alternative, because nearly all of those who apply for a PGY-1 slot have completed an AOA-approved internship. Although the American Board of Family Practice recognizes the osteopathic internship as the educational equivalent of the PGY-1 year, most DOs are willing to repeat the PGY-1 year in family practice. ${ }^{8}$ To offset the migration of $\mathrm{MD}$ graduates of American medical schools who gravitated toward surgical and subspecialty fields, conscious efforts were made to recruit DOs to fill the void. In 1981 , for example, DOs represented only $2.3 \%$ of all PGY-1 residents in ACGME-approved family practice programs; by 1987 , that representation had increased to $6.8 \% .^{9}$

In the $1980 \mathrm{~s}$, the movement of DOs into allopathic residencies helped diffuse a demographic time bomb within the osteopathic medical profession. Without the allopathic medical option for interns, the osteopathic medical educational system would have collapsed under the sheer weight of numbers. In 1988, the 1355 DO interns looking at the full slate of osteopathic medical residencies saw a total of 873 first-year slots. ${ }^{10(\mathrm{p} 519)}$ This number assumes all AOA-approved residency slots were funded, a best-case, but unrealistic, scenario. Using the more reasonable percentage $70 \%$ of approved positions funded in 1988 , interns calculated that their chance of obtaining any osteopathic medical residency - without considering choice of specialty-was only $45 \%$. Under these circumstances, it is understandable that young DOs were seeking out opportunities in ACGME-approved programs at the same time that allopathic program directors were attempting to recruit more osteopathic physicians.

It must be noted that the number of osteopathic residency positions had indeed increased. In 1982, the AOA had 1377 approved positions in the major medical specialties. By 1988 , the number of slots had increased to 1854 , or by $35 \%$. Much of this growth can be attributed to the efforts of the osteopathic medi- cal colleges. Despite these gains, over the same period the percentage of approved versus filled residency positions fluctuated only marginally, hovering between $63 \%$ and $72 \%$. Overall, approximately one of every three AOA-approved positions remains vacant either because the position is not funded by a hospital or because it does not attract osteopathic physicians. A high vacancy rate has been a constant feature at times of dramatic change in medical education. By way of contrast, 81,093 of $84,983(96 \%)$ ACGME-approved residency positions were filled in $1988 .^{7(\mathrm{pp} 1030-1031)}$

Measurement of DO crossovers into ACGME-approved residencies can be gauged in different ways. Remarkably, a statistical summary of the results of the NRMP for 1983 through $1988,{ }^{11}$ indicates that the percentage of DOs selected for these residencies remained relatively stable, at around $66 \%$. What is dramatically different is that the total number of active candidates on match day greatly increased. During these 6 years, the number of DOs chosen in the NRMP increased from 94 to 409 . However, these data represent only a partial picture because the NRMP is a voluntary program and many DOs are selected outside the match.

Another way to measure the crossover is to compare the data published in the Journal of the American Medical Association ${ }^{7(\mathrm{p} 1036), 12(\mathrm{p} 1100)}$ and in the American Osteopathic Association Yearbook and Directory. ${ }^{10(p p 518,519)}$ Table 1 shows the rate of growth in the number of DOs training in allopathic and osteopathic residency programs for 1985 and 1988 . The osteopathic medical profession had a net increase of 228 residents, about 75 of them resulting from the family practice residency's shifting from a 1- to a 2-year program. With no increase in training years, the ACGME-approved programs were able to increase the number of their DOs by 770 , more than three times the gains of the AOA-approved programs. Of this number, $526(68 \%)$ entered residencies in family practice, internal medicine, or pediatrics.

\section{High cost of the DO crossover}

The release of pressure on the osteopathic medical educational system comes at a high price 


\begin{tabular}{|c|c|c|c|c|c|c|}
\hline \multicolumn{7}{|c|}{$\begin{array}{l}\text { Table } 1 \\
\text { DO Resident Population in Allopathic and Osteopathic } \\
\text { Resident Programs, } 1985 \text { and } 1988\end{array}$} \\
\hline \multirow[b]{2}{*}{ Specialty } & \multicolumn{3}{|c|}{$\begin{array}{l}\text { No. of DOs in } \\
\text { allopathic } \\
\text { programs }\end{array}$} & \multicolumn{3}{|c|}{$\begin{array}{l}\text { No. of DOs in } \\
\text { osteopathic } \\
\text { programs }\end{array}$} \\
\hline & 1985 & 1988 & Gain & 1985 & 1988 & Gain \\
\hline Anesthesiology & 79 & 122 & 43 & 88 & 90 & 2 \\
\hline Emergency medicine & 48 & 73 & 25 & 45 & 85 & 40 \\
\hline Family medicine & 318 & 584 & 266 & 195 & 318 & 123 \\
\hline Internal medicine & 288 & 486 & 198 & 257 & 261 & 4 \\
\hline Neurology & 37 & 51 & 14 & 6 & 12 & 6 \\
\hline Obstetrics/gynecology & 77 & 109 & 32 & 105 & 110 & 5 \\
\hline Pathology & 28 & 35 & 7 & 8 & 12 & 4 \\
\hline Pediatrics & 73 & 135 & 62 & 20 & 27 & 7 \\
\hline $\begin{array}{l}\text { Physical medicine and } \\
\text { rehabilitation }\end{array}$ & 44 & 60 & 16 & 2 & 3 & 1 \\
\hline Psychiatry & 94 & 174 & 80 & 9 & 29 & 20 \\
\hline Surgery & 6 & 33 & 27 & 180 & 196 & 16 \\
\hline Net 4-year gain & & & 770 & & & 228 \\
\hline
\end{tabular}

to the profession. Many of the osteopathic physicians who took allopathic residencies have drifted away and dropped their affiliation with the AOA. ${ }^{13}$ The limited opportunities for DOs to have their allopathic residencies approved through the AOA drove many to pursue allopathic certification. For example, as of the 1988-1989 academic year, only 276 of 2150 (12.8\%) DOs in allopathic residencies had obtained AOA approval; these include 10 of 584 osteopathic physicians in family practice and 3 of 486 in internal medicine. ${ }^{7(p 1036), 14}$ Admittedly these numbers include a relatively small number of DOs who bypassed the osteopathic internship and cannot qualify for approval. However, the large majority of those with an AOA-approved internship did not meet existing $\mathrm{AOA}$ requirements or chose not to seek AOA recognition of their allopathic residency.

The osteopathic hospitals that are hurt most by the crossover trend are the smaller, community-based hospitals, which depend heavily on primary care physicians for their referral patterns and support. In the past, operating a family practice residency allowed these osteopathic hospitals to train and attract young physicians to their communities. If these same facilities are unable to attract allopathically trained DOs, the flow of fresh blood will be curtailed significantly, and the future viability of the institutions will be jeopardized. If the axiom holds true that "residents remain near where they train," a reduction in the return flow of DOs to osteopathic hospitals will to an even greater extent harm the already-reeling osteopathic hospital network.

Throughout much of the 1980 s, AOA policy sent a consistent and chilly message to interns who chose ACGME-approved residencies. Before they could obtain AOA approval of an allopathic residency, these interns were first required to make a detailed, documented effort to secure an available and funded osteopathic residency in the same specialty. The logic of this policy was to supply osteopathic hospitals with the number of residents needed to develop and expand osteopathic postdoctoral programs and also to penalize interns who bypassed osteopathic medical residencies. In the eyes of many, a greater premium was placed on loyalty to the profession than on educational quality. The requirement was abandoned after the AOA recognized that osteopathic institutions could not generate sufficient numbers of resi- 
dency positions and, more critically, after the AOA saw graduating interns ignoring the policy.

As aforenoted, younger DOs are gravitating toward allopathic residencies without bothering to obtain AOA approval or certification. The greatest potential harm to the AOA is the loss of these individuals as lifetime members. A direct link exists between AOA membership and osteopathic certification. Because the AOA is a recognized certifying agency for osteopathic physicians, AOAcertified DOs who voluntarily drop their membership also lose their certification status. Thus, it is in the interest of the AOA to certify qualified candidates because they must remain members in good standing of the AOA for their active, professional life. The Board of Trustees recently eliminated its long-standing policy and created a new "amnesty" program to bring DOs with allopathic credentials back into the fold and to encourage them to seek osteopathic certification. In sum, AOA policy has shifted 180 degrees: what was considered taboo yesterday is seen as acceptable today.

The challenge facing the osteopathic medical educational system is, How can osteopathic medical education be stabilized and controlled? Perhaps the recently adopted open-door policy that welcomes DOs into ACGME-approved programs, coupled with the increasing interest of osteopathic physicians themselves in allopathic residencies, has produced more than the desired amount of change. In the past, the osteopathic medical educational system operated as a self-contained entity. Its "separate but equal" approach maintained a unique professional identity, which was reinforced by barriers that made it difficult for DOs to move in MD educational circles. As noted, these barriers are beginning to crumble, particularly in the primary care specialties, and the osteopathic medical profession is losing its educational grip over its own graduates.

The osteopathic medical profession has always functioned under the assumption that the natural order of things was for students to become interns and for interns to move up into residencies-all under the osteopathic medicine banner. In short, it never had to com- pete against allopathic medical education programs for its own interns. When the allopathic challenge came after 1984, osteopathic medical educators were attempting to resolve internal problems on how to expand medical education programs with a shrinking osteopathic hospital network and still contend with a surplus number of graduates coming out of their colleges.

Osteopathic hospitals have been caught up in the same changing business climate that has affected all hospitals. Those that have made critical adjustments to new federal policies, new methods of organization, and new market conditions have survived and prospered. Not every institution has made correct decisions, with the result that there have been mergers, outright acquisitions, and in some cases, closures. The time has not been ripe to expand hospital-based educational programs in osteopathic medical facilities because the patient census has decreased, the length of hospital stay has decreased, and the use of outpatient services has increased. With fewer osteopathic hospitals and a lower capability of supporting existing programs, how can the osteopathic medical educational system extend its postdoctoral programs without sacrificing quality? Educators have addressed themselves to that problem; but the problem has not been resolved and from all appearances will continue into the future.

The expansionist wave that saw ten new colleges of osteopathic medicine come on line between 1969 and 1981 is over, and the total number of graduates has stabilized at around 1600 per year. The sudden increase in the number of graduates would have overwhelmed even a robustly healthy osteopathic hospital network, however. For example, in 1980, the total student enrollment in all osteopathic colleges was 4924 ; in 1987 , it was 6600 , representing an increase of $34 \% .^{10(\mathrm{p} 523)}$ Herculean efforts were undertaken to ensure an adequate supply of internship positions for all graduates, but these gains came at the expense of planned growth for residency programs. Despite these demographic handicaps, at least the number of graduates has topped out and will remain constant-as long as no new colleges of osteo- 


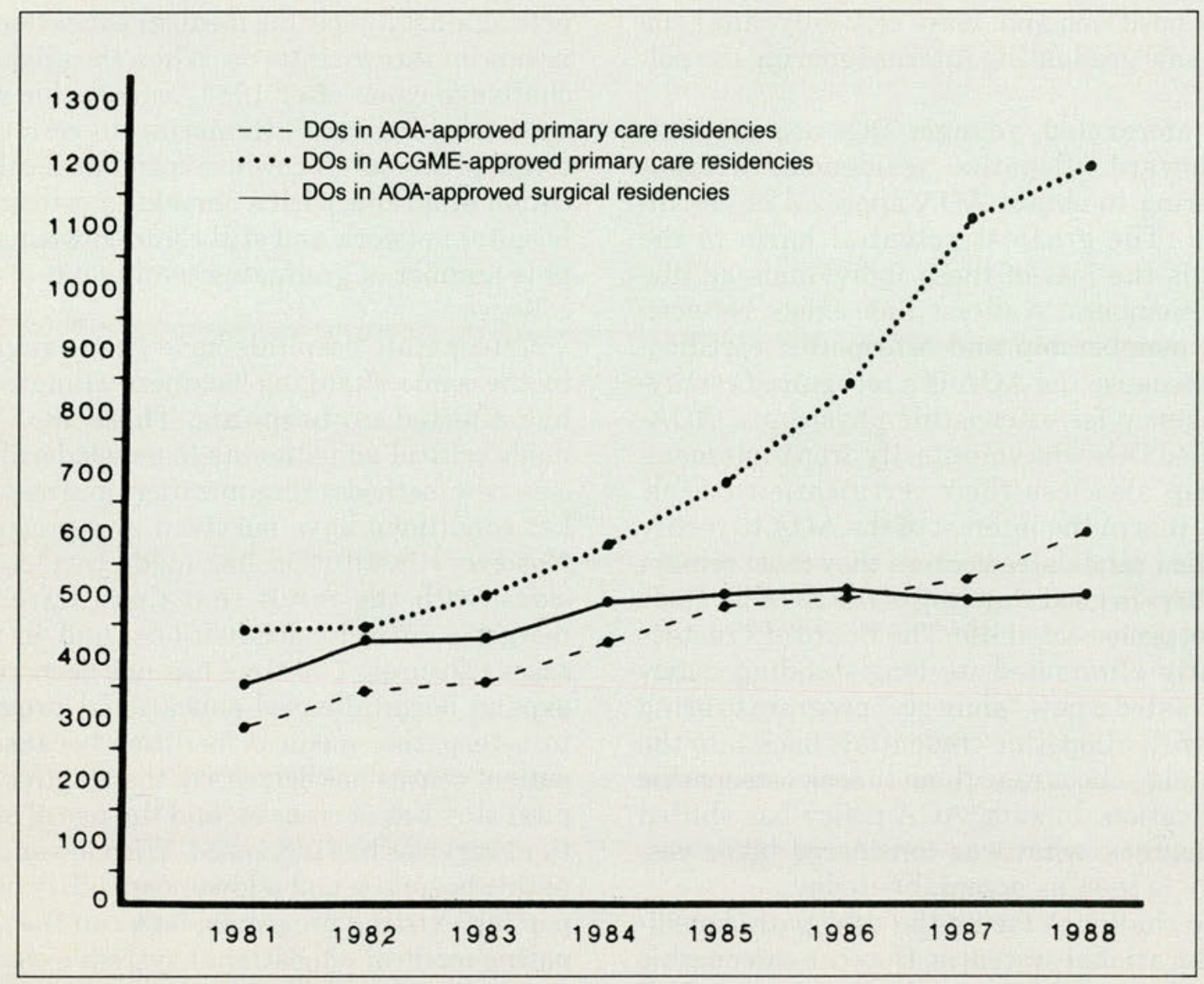

Figure. DOs in primary care versus surgical residencies, 1981 through 1988. Primary care residencies include family practice, internal medicine, and pediatrics. Surgical residencies include general surgery, orthopedic surgery, obstetrics and gynecologic surgery, urology, ophthalmology, otorhinolaryngology and orofacial surgery, neurologic surgery, and thoracic/cardiovascular surgery. (See also Table 2).

pathic medicine are allowed to open their doors. Although the problems confronting the osteopathic hospital network have not ended, osteopathic medical educators can at least begin building postdoctoral programs that are based on apparently constant numbers of interns and residents for the near future.

\section{Security of osteopathic surgical residencies}

Surgical residencies are the most secure element of the osteopathic medical educational system. These programs are immune to the crossover trend because of the intense competition among MDs for ACGME-approved programs and also because of the conscious pol- icy on the part of ACGME program directors not to select osteopathic physicians as residents in surgery. Only 33 out of a total of 7739 residents in general surgery (ACGME) are DOs, and most of these are training in military programs. ${ }^{7(\mathrm{pp} 1030,1036)}$

It was not until 1985 that the American Board of Surgery changed its bylaws to permit a DO who had successfully completed an ACGME-approved residency in general surgery to qualify for board eligibility under its certification requirements. $^{8(\mathrm{p} 652)}$ If a DO wants a residency in a cutting specialty, his opportunities are, for the most part, limited to osteopathic residency programs. Needless to say, the supply of these slots does not match the 
Table 2

DOs in Primary Care Versus Surgical Residencies, 1981 through 1988

\begin{tabular}{|c|c|c|c|c|c|c|c|c|}
\hline \multirow[b]{2}{*}{ Residency } & \multicolumn{8}{|c|}{ No. of DOs } \\
\hline & 1981 & 1982 & 1983 & 1984 & 1985 & 1986 & 1987 & 1988 \\
\hline \multirow{3}{*}{$\begin{array}{l}\text { AOA-approved } \\
\text { primary care* } \\
\text { ACGME-approved } \\
\text { primary care* } \\
\text { AOA-approved } \\
\text { surgical } \dagger\end{array}$} & 272 & 342 & 360 & 437 & 472 & 491 & 523 & 606 \\
\hline & 443 & 445 & 489 & 573 & 679 & 846 & 1114 & 1205 \\
\hline & 354 & 424 & 430 & 483 & 504 & 496 & 482 & 501 \\
\hline
\end{tabular}

demand. There is little growth potential, however, as long as the osteopathic hospital network continues to shrink and the number of surgeries declines. As shown in the Figure and Table 2, there were fewer residents training in surgical specialties in 1988 than there were in 1985 .

Between 1980 and 1985, there was a modest increase in the total number of DOs training in AOA-approved surgical residencies. In 1936, a downturn occurred. To a certain extent, the loss of osteopathic hospitals and more difficult times for hospitals are to blame. Nationally, a growing number of surgical procedures are being performed on an outpatient basis. (See the Figure and Table 2 for a comparison of the number of DOs in surgical residencies with the numbers in AOA- and ACGME-approved primary care residencies for the years 1981 to $1988^{8,10(p p 518,519), 15-17}$ What can be seen is a slight growth in the number of DOs in the osteopathic primary care residencies and a dramatic growth since 1984 in the number of DOs in ACGME-approved residencies. This surge coincides with the period in which the number of osteopathic interns was at an all-time high and in which MD interest in ACGME-approved primary care residencies began to wane noticeably.

In other areas of medicine, the osteopathic medical educational system cannot compete, and therefore DOs with a professional interest in these noncompetitive specialties have no alternative other than allopathic residen- cies. Programs such as child and adult psychiatry, public health/preventive medicine, and rehabilitation medicine require specialized healthcare facilities that, with rare exceptions, do not exist in the osteopathic hospital network. Dermatology, neurology, nuclear medicine, and subspecialties of radiology require teaching services and research units that are found only at the largest of tertiary-care hospitals. Lacking these educational resources, DOs by necessity have traditionally turned to the ACGME-approved programs for training.

\section{Entering the 1990s}

The direct challenge now facing the osteopathic medical educational system lies in the areas of family practice, internal medicine, pediatrics, and to a lesser extent, anesthesiology, obstetrics/gynecology, emergency medicine, radiology, and pathology. These are all areas that have witnessed a significant upturn in the number of DOs crossing over to ACGMEapproved programs at the expense of AOAapproved residencies. From both an educational and a political perspective, the primary care programs especially are of major concern to the AOA.

As mentioned before, the osteopathic hospital network is limited in the types of residency programs it can support, and primary care represents its heart and soul. Losses felt here threaten the foundation of the osteopathic medical educational system. If the "melt-away" factor reaches sufficient proportions, primary 
care programs will dry up because of a lack of applicants, osteopathic hospitals will voluntarily withdraw from residency training, and subspecialty programs in medicine will suffer because of the lack of DOs training in internal medicine at osteopathic hospitals. The osteopathic hospitals cannot shift their emphasis in other educational directions.

Politically, the AOA has consistently championed primary care medicine. As an issue, primary care came into vogue in the 1980 s as federal and state officials, health planners, and public interest groups all stood as one in their desire to promote its expansion and to place limitations on the training of specialists. With its enviable track record in training physicians for primary care careers, the profession finds itself edging toward the spotlight of acclaim in a good position to reap the benefits of proposed federal and state changes that would offer sizable financial rewards for development and expansion in primary care residencies. Many of the AOA's past achievements will be diminished in terms of future political and economic importance if the majority of DOs training in primary care programs are found in ACGME-rather than AOA-approved residencies.

With everything that is at stake, the decision makers who will determine the future are not the AOA Board of Trustees, educational committees, hospitals, or even program directors. It is the collective might of individual osteopathic interns making their decisions for residency training. Those whose interests lie in primary care fields now have the unparalleled opportunity to chose between allopathic and osteopathic residency programs. If the vast majority select allopathic residency programs, the current problems threatening the osteopathic medical educational system and hospital network will only become exacerbated and seriously diminish the AOA's prestige and selfconfidence as well as shake the educational foundations of the profession.

If a larger number of DO interns stay within the osteopathic medical family for their residency education, the osteopathic educational system will have met the challenge of their pull toward the MD vacuum and emerge stronger from the experience. The final outcome will be known only in years to come. From the data shown in Table 2, however, the current attraction of osteopathic interns to allopathic primary care residencies appears to be strong indeed.

By and large, DO interns are oblivious to their collective power and the significance of their decisions. They are making career choices that are based on individual professional aspirations. Their criteria remain unchanged, in that priorities are determined by perceived quality of the program, geographic location as a place of residence, compensation and benefits package offered, and future practice potential for a career. Today's osteopathic interns make little distinction between allopathic and osteopathic postdoctoral programs because opportunities exist for them in each camp. Indeed, because of the shortage of available and funded first-year osteopathic residency slots, interns are actually forced to apply to allopathic postdoctoral programs. It is not likely that as they weigh personal and professional goals in their decision-making, osteopathic interns take into account any potential impact of their choices on the profession.

From an intern's point of view, there are pros and cons in both osteopathic and allopathic primary care residencies. In nearly all instances, allopathic residencies pay more than osteopathic residencies in the same disciplines do. With an average indebtedness of $\$ 60,000$, osteopathic interns have to contend with paying off their educational loans and having a reasonable standard of living while serving a residency. ${ }^{18}$

Geographic considerations also favor the allopathic programs, for they have a truly national education system. Many of the newest osteopathic medical colleges, on the other hand, are located in regions of the country in which there are few osteopathic residencies. Interns who graduate from these colleges tend to find local allopathic residencies more attractive because they are located closer to the places in which they want to live and eventually practice medicine. More and more, owing to the increase in dual-career families, professional mobility is becoming a major factor 
in residency selection. The bulk of the osteopathic residencies are located in the Midwest, and thus these programs tend to attract primary care residents who have trained as students and interns in the surrounding region.

The osteopathic medical profession has several factors in its favor. By virtue of belonging to the osteopathic medical family and knowing the hospital and its teaching faculty, the intern has a higher comfort level. Practice opportunities can be greater in a program in which graduates are encouraged to remain on staff and are provided with a "seeding" program after the residency. In the case of family practice, the intern can usually save 1 year of training: the osteopathic medicine model requires a total of 3 years of postdoctoral education, in comparison with the common sequence of DOs completing an osteopathic internship followed by 3 years of family practice.

Educational quality is another major consideration in the decision-making process. With the increase in allopathic residency opportunities, interns now have the chance to make a side-by-side comparison of AOA- and ACGME-approved programs in terms of what they offer educationally. This means that potential candidates can now measure osteopathic residencies in internal medicine, family practice, and pediatrics against what is available to them in allopathic residencies.

Osteopathic residency programs that meet or exceed the allopathic competition in educational quality will continue to thrive. The programs that interns shy away from either will not draw any candidates or will have to be upgraded if they intend to compete. Because the combined number of allopathic and osteopathic residency positions far exceeds the supply of active candidates, the osteopathic intern who is seeking a primary care residency will be in the driver's seat for the foreseeable future.

During the past 6 years, ACGME-approved programs have had the competitive edge in the ability to attract osteopathic physicians. At present, the ratio of DOs in allopathic residencies to those in osteopathic primary care residencies is greater than 2 to 1 . The ability of the osteopathic medical educational system to react has been severely hampered by a shrink- ing base of osteopathic hospitals. The osteopathic hospitals cannot contract and expand at the same time. To date, the AOA response has been limited to proposing curricular changes and pressuring the colleges of osteopathic medicine to do more toward generating additional internship and residency positions.

Some of the colleges have responded by initiating college-based postdoctoral programs in hospitals with mixed but largely allopathic physician staffs. Considering all the other options, these types of educational arrangements appear to offer the best hope for the future.

How the osteopathic postdoctoral system will fare in the future rests with the students who are currently enrolled in osteopathic colleges. If these students bypass AOA-approved residencies in sufficient numbers and in critical specialties, osteopathic medical education will be characterized by its emphasis on training osteopathic surgeons. The membership and prestige of the parent organization will also be adversely affected.

On the positive side, the competition being waged in the field of medical education may ignite the energies of the osteopathic medical profession and inspire it to make a greater commitment to improving its educational system. The reality that two out of every three DOs in a primary care specialty can be found in an ACGME-approved program should provide a sufficient impetus to meet this challenge.

The author acknowledges the Media Department of the New York College of Osteopathic Medicine of New York Institute of Technology for producing the Figure and the Tables.

1. American Medical News, vol 17, February 1989, p 29.

2. Kletke PR, Schleiter MK, Tarlov AR: Changes in the supply of internists: The internal medicine population from 1978 to 1989. Ann Intern Med 1987;107:93-100.

3. Graettinger JS: Internal medicine in the National Matching Program 1987: The Ides of March. Ann Intern Med 1988;108: 101-115.

4. Scherr L: Decline in internal medicine careers: A foreboding trend. ACP Observer 1987;2:22.

5. Colwill JM: Primary care education: A shortage of positions and applicants. Fam Med 1988;20(4):250-254.

6. Graettinger JS: AAMC data report: 1989 NRMP results. Academic Medicine 1989;64(8):486-488. 
7. Etzel SI, Egan RL, et al: Graduate medical education in the United States. JAMA 1989;262:1029-1037.

8. 1987-1988 Directory of Graduate Medical Education Programs. Chicago, Ill, American Medical Association, 1987, pp 572,652 .

9. Schmittling G: Entry of U.S. medical school graduates into family practice residencies: 1987-1988. Fam Med 1988;20:367. 10. AOA Yearbook and Directory of Osteopathic Physicians, 1987 1988. Chicago, Ill, American Osteopathic Association, 1987, pp $518,519,523$.

11. Listing of Candidates Participating in the Matching Program for 1988. Evanston, Ill, National Resident Matching Program, 1988.

12. Crowley AE, Etzel SI: Graduate medical education in the United States. JAMA 1988;260:1093-1101.

13. American Medical News, April 8, 1988, p 8.

14. Ward D, Baker $\mathrm{HH}$ : Osteopathic postdoctoral education in transition. JAOA 1988;88:1389-1397.

15. AOA Yearbook and Directory of Osteopathic Physicians, 19851986. Chicago, Ill, American Osteopathic Association, p 495.

16. Crowley AE: Summary statistics on graduate medical education in the United States. JAMA 1984;252:1545-1553.

17. Crowley AE, Etzel SI, Shaw HA: Graduate medical education in the United States. JAMA 1987;258:1031-1040.

18. Debt and Career Plans of Osteopathic Students in 1987. Rockville, Md, American Association of Colleges of Osteopathic Medicine, 1988. 